\title{
Erratum to: New Design Techniques for Globally Convergent Simultaneous Localization and Mapping: Analysis and Implementation
}

Pedro Lourenço, Bruno Guerreiro, Pedro Batista, Paulo Oliveira and Carlos Silvestre

Erratum to:

New Design Techniques for Globally Convergent Simultaneous Localization and Mapping: Analysis and Implementation in: T.I. Fossen et al. (eds.), Sensing and Control for Autonomous Vehicles, Lecture Notes in Control and Information Sciences 474, https://doi.org/10.1007/978-3-319-55372-6_6

In the original version of the book, missing author name "Jeffrey Uhlmann" in reference 11 of Chapter 6 has to be added. The erratum chapter and the book have been updated with the change.

The updated online version of this chapter can be found at https://doi.org/10.1007/978-3-319-55372-6_6 